\title{
Individual and poly-substance use and condomless sex among HIV-uninfected adults reporting heterosexual sex in a multi-site cohort
}

R. J. Fredericksen ${ }^{1 *}$ (D, B. M. Whitney ${ }^{1}$, E. Trejo ${ }^{1}$, R. M. Nance ${ }^{1}$, E. Fitzsimmons ${ }^{1}$, F. L. Altice ${ }^{2}$, A. W. Carrico ${ }^{3}$, C. M. Cleland ${ }^{4}$, C. Del Rio ${ }^{5}$, A. Duerr', W. M. El-Sadr', S. Kahana ${ }^{8}$, I. Kuo ${ }^{9}$, K. Mayer $^{10}$, S. Mehta ${ }^{11}$, L. J. Ouellet ${ }^{12}$, V. M. Quan ${ }^{13}$, J. Rich $^{14}$, D. W. Seal ${ }^{15}$, S. Springer ${ }^{16},{\text { F. } \text { Taxman }^{17} \text {, W. Wechsberg }}^{18}$, H. M. Crane ${ }^{1}$ and J. A. C. Delaney ${ }^{19}$

\begin{abstract}
Background: We analyzed the association between substance use (SU) and condomless sex (CS) among HIVnegative adults reporting heterosexual sex in the Seek, Test, Treat, and Retain (STTR) consortium. We describe the impact of SU as well as person/partner and context-related factors on CS, identifying combinations of factors that indicate the highest likelihood of CS.

Methods: We analyzed data from four US-based STTR studies to examine the effect of SU on CS using two SU exposures: 1) recent SU (within 3 months) and 2) SU before/during sex. Behavioral data were collected via 1:1 or self-administered computerized interviews. Adjusted individual-study, multivariable relative risk regression was used to examine the relationship between CS and SU. We also examined interactions with type of sex and partner HIV status. Pooled effect estimates were calculated using traditional fixed-effects meta-analysis. We analyzed data for recent SU ( $n=6781 ; 82 \%$ men, median age $=33$ years) and SU before/during sex $(n=2915 ; 69 \%$ men, median age $=40$ years).

Results: For both exposure classifications, any SU other than cannabis increased the likelihood of CS relative to non-SU $(8-16 \%$, $p$-values< 0.001$)$. In the recent SU group, however, polysubstance use did not increase the likelihood of CS compared to single-substance use. Cannabis use did not increase the likelihood of CS, regardless of frequency of use. Type of sex was associated with CS; those reporting vaginal and anal sex had a higher likelihood of CS compared to vaginal sex only for both exposure classifications $(18-21 \%, p<0.001)$. Recent SU increased likelihood of CS among those reporting vaginal sex only $(9-10 \%, p<0.001)$; results were similar for those reporting vaginal and anal sex $(5-8 \%, p<0.01)$. SU before/during sex increased the likelihood of CS among those reporting vaginal sex only $(20 \% ; p<0.001)$ and among those reporting vaginal and anal sex $(7 \% ; p=0.002)$. Single- and polySU before/during sex increased the likelihood of CS for those with exclusively HIV-negative partners (7-8\%, $p \leq$ 0.02), and for those reporting HIV-negative and HIV-status unknown partners (9-13\%, $p \leq 0.03)$.
\end{abstract}

\footnotetext{
* Correspondence: rfrederi@uw.edu

'UW Center for AIDS Research, Harborview Medical Center, 325 Ninth Avenue, Box 359931, Seattle, WA 98104-2499, USA

Full list of author information is available at the end of the article
}

(c) The Author(s). 2021 Open Access This article is licensed under a Creative Commons Attribution 4.0 International License, which permits use, sharing, adaptation, distribution and reproduction in any medium or format, as long as you give appropriate credit to the original author(s) and the source, provide a link to the Creative Commons licence, and indicate if changes were made. The images or other third party material in this article are included in the article's Creative Commons licence, unless indicated otherwise in a credit line to the material. If material is not included in the article's Creative Commons licence and your intended use is not permitted by statutory regulation or exceeds the permitted use, you will need to obtain permission directly from the copyright holder. To view a copy of this licence, visit http://creativecommons.org/licenses/by/4.0/ The Creative Commons Public Domain Dedication waiver (http://creativecommons.org/publicdomain/zero/1.0/) applies to the data made available in this article, unless otherwise stated in a credit line to the data. 
Conclusion: Except for cannabis, any SU increased the likelihood of CS. CS was associated with having perceived

HIV-negative partners and with having had both anal/vaginal sex.

Keywords: Substance use, Condom use

\section{Background}

Sexually transmitted infections (STIs) including HIV disproportionately affect socially and economically marginalized populations [1] including African-Americans, Latinos, men who have sex with men (MSM), including bisexual men that also have sex with women, transgender women, and those currently or formerly incarcerated [2-9]. Beyond abstinence, condoms are the most effective means of preventing most STIs. The use of intoxicants prior to sex is a well-known barrier to condom use, [10-12] and substance use (SU) is common among many of the populations at greatest risk for contracting STIs/HIV [13-15].

Much heterogeneity exists among studies in the strength of associations between SU and condomless sex (CS), particularly between those studies with different methodologies and recall periods [16-19]. The literature suggests general associations between alcohol consumption, CS, and HIV risk, though the studies do not establish a causal relationship. More rigorous multiple event-level analyses have provided the temporal sensitivity to assess causality, from which there have been mixed findings [17, 20-23]. Event-level analyses for CS in the context of substances other than alcohol have varied by substance: while methamphetamine use, cocaine, and illicit opioids have been associated with CS [22-26], effects for cannabis use have been mixed [20, 21, 23, 27-30].

Additionally, the association of SU with CS has been found to vary substantially by gender and partner characteristics [31], HIV status [32], nature of relationship (i.e. primary vs. casual vs. transactional) [33], number of substances used [34], combination of substances used $[32,35]$, and pattern of substance use [10,33].

Previous studies of condom use behavior in the context of substance use among HIV-uninfected adults reporting heterosexual sex in the U.S. have not specified type of sex (e.g., anal vs. vaginal), have been substancespecific, or have had limited sample size. To better understand the relationship between SU and CS, we analyzed CS among a large cohort of HIV-uninfected adults reporting heterosexual sex in the context of SU, derived from the harmonized dataset of the National Institute of Drug Abuse (NIDA) Seek, Test, Treat, and Retain (STTR) HIV-prevention and treatment research initiative [36]. We describe the association between substance-related, person/partner related, and contextrelated factors and condom use. In the process we identify the combinations of factors that indicate the highest risk of CS, and hence potential for STI transmission. We hypothesize that a) persons who use multiple substances over the course of the reference period (polysubstance use) will be more prone to CS than single-substance users and non-users; b) persons who use any type of substance right before or during sex are at a higher risk of CS than persons who do not use substances before/ during sex; and c) the degree of increased risk of CS in persons who use substances (PWUS) will vary depending on substance type and demographic factors (age, gender, race).

\section{Methods}

Seek, test, treat, and retain (STTR) data collection and harmonization initiative

STTR was initiated by the National Institute on Drug Abuse and combines data from observational studies and trials intended to improve outcomes along the HIV care continuum for people involved in the criminal justice system and other vulnerable populations, many of whom have substance use disorders [36, 37]. Four USbased STTR studies contributed data to these analyses in order to enhance demographic, clinical, and geographic diversity. These were Brooklyn Community Action Project (BCAP, Brooklyn, NY); Baltimore-Rhode Island Get HIV Tested (BRIGHT, Baltimore, MD and Providence, RI); Seek, Test, and Retain (STAR, New York, NY); and Seek, Test, and Treat Strategies (STTS, Milwaukee County, WI). BRIGHT and STTS consisted of populations involved with the criminal justice system (probationers, parolees, and recent detainees about to be released); BCAP and STAR consisted of populations at high risk of HIV acquisition due to lifestyle factors (Table 1). We selected studies from the STTR consortium based on availability of illicit drug and alcohol use data, hereinafter referred to as substance use, and sexual risk behavior data. All participants $\geq 18$ years of age who reported sexual activity were eligible for inclusion. Data were collected between 12/2011 and 06/2015.

\section{Recruitment and sampling}

BCAP and STAR used respondent-driven incentivized seed-based recruitment. BRIGHT and STTS used convenience sampling, with BRIGHT recruiting via flyers and posters within a community corrections office, and STTS by uniformly approaching all new detainees to invite participation. Data were collected either via structured self-administered computerized interview (BCAP, 
Table 1 STTR studies

\begin{tabular}{|c|c|c|c|c|c|c|}
\hline Study & Geographic Location & Population & $\begin{array}{l}\text { Recent } \\
\text { substance } \\
\text { use }\end{array}$ & $\begin{array}{l}\text { Substance use } \\
\text { before/during sex }\end{array}$ & $\begin{array}{l}\text { Reference } \\
\text { Period }\end{array}$ & $\begin{array}{l}\text { Participants } \\
\text { Contributing Data }\end{array}$ \\
\hline BCAP & Brooklyn, NY & $\begin{array}{l}\text { Heterosexual individuals at high risk } \\
\text { for HIV infection }\end{array}$ & Yes & Yes & 30 days & $2133(31.5)$ \\
\hline BRIGHT & $\begin{array}{l}\text { Baltimore City, MD \& } \\
\text { Providence, RI }\end{array}$ & Probationers/ parolees & Yes & No & 90 days & $1537(22.7)$ \\
\hline STAR & New York, NY & $\begin{array}{l}\text { African American substance-using } \\
\text { men at risk for STI/HIV }\end{array}$ & Yes & Yes & 30 days & 768 (11.3) \\
\hline STTS & Milwaukee County, WI & $\begin{array}{l}\text { Detainees in the Wisconsin prison } \\
\text { system detention center }\end{array}$ & Yes & No & 90 days & $2343(34.6)$ \\
\hline TOTAL & & & & & & 6781 \\
\hline
\end{tabular}

Abbreviations: BCAP Brooklyn Community Action Project, BRIGHT Baltimore-Rhode Island Get HIV Tested, STAR Seek, Test, and Retain, STTR Seek, Test, and Treat Strategies

STTS) or by trained research interviewers (BRIGHT, STAR).

\section{Data sources}

The STTR data repository integrates data from STTR studies, including clinical data such as standardized HIV-related information, as well as demographic, HIV transmission risk factors, and SU data obtained from enrollment interviews. All SU and CS variables focused on recent activity defined as the prior 1-3 months (timeframes were either 30 or 90 days). For studies including incarcerated participants, only non-incarcerated timeframes prior to incarceration were included. All studies used a variation of the AUDIT for alcohol use, with the exception of BCAP, which asked a single item querying frequency of alcohol use in the past 30 days. For drug use, all studies used variations of the ASSIST appropriate for individual study goals and population needs. SU was parameterized as a binary exposure (yes/no) and was defined as use of any of the following substances: binge alcohol (defined as $\geq 5$ drinks per day for men and $\geq 4$ for women), illicit opioids, cocaine/crack, methamphetamines/ stimulants, and other substances (e.g., hallucinogens, inhalants, barbiturates, synthetic drugs). An additional parameterization of illicit SU was also evaluated, which included the same drugs as above with the exception of binge alcohol use and cannabis (any alcohol use and/or cannabis use were included in the referent group). Participants were also asked about the timing of SU (before/during), sexual activity, and condom use over the recall period. Two overall SU exposure variables were created for analysis: 1) Any SU during the reference period, hereinafter referred to as recent substance use, and more specifically, 2) SU before or during sex. Main analyses did not include cannabis as our preliminary findings showed no association between cannabis and CS. We did, however, conduct sensitivity analyses including cannabis as an exposure. Each participant was categorized as either a non-user, a single- substance user, or a polysubstance user. SU before/during sex was included as a binary exposure (yes/no) from two of the included studies (Table 1). The outcome, engagement in any CS during the recall period, was harmonized across studies as a binary variable (yes/no).

\section{Statistical analyses}

All statistical analyses was performed in Stata version 14 [38].

\section{Recent substance use}

We examined demographic characteristics (including age, gender, race/ethnicity, sexual orientation, and education) and HIV risk factors both overall and by SU category (Table 2). We used individual-study, multivariable relative risk regression with robust confidence intervals to examine the relationship between CS among singleand poly-substance users compared to non-users [39]. Final models included age, race/ethnicity, and gender. Pooled effect estimates were calculated using traditional fixed-effects meta-analysis because we did not believe naïve pooling was appropriate given the heterogeneity of the study populations [40]. Additional analyses stratified by type of sex (vaginal sex only or vaginal and anal sex, from all 4 studies) and by partner self-reported HIV status (HIV-negative partners only, HIV-status unknown partners only, or HIV-negative and HIV-status unknown partners; data available from BRIGHT and STAR only). We assessed interaction between type of sex and substance use category as well as partner(s)' self-reported HIV status and substance use category, however, we were not specifically powered to detect statistical interaction. Sensitivity analyses including cannabis as a substance and by recall period (30 or 90 days) were also conducted.

\section{Substance use before/during sex}

We examined demographic and clinical characteristics by $\mathrm{SU}$ before/during sex. We used individual-study, 
Table 2 Demographic characteristics by substance use category - Recent substance use

\begin{tabular}{|c|c|c|c|c|c|}
\hline & & & Substance & tegory & \\
\hline & & Total & None & Single-Substance & Polysubstance \\
\hline $\mathbf{N}$ & $N$ & 6781 & $3292(48.6)$ & $2222(32.8)$ & $1267(18.7)$ \\
\hline Male & 6781 & $5573(82.2)$ & $2623(79.7)$ & $1814(81.6)$ & $1136(89.7)$ \\
\hline Age & 6781 & $33(26-45)$ & $32(25-44)$ & $34(26-45)$ & $37(27-47)$ \\
\hline Race/Ethnicity & 6781 & & & & \\
\hline Black or African American & & $4073(60.1)$ & $2246(68.2)$ & $1280(57.6)$ & $547(43.2)$ \\
\hline White & & $748(11.0)$ & $252(7.7)$ & $209(9.4)$ & $287(22.7)$ \\
\hline Hispanic or Latino & & $1588(23.4)$ & $620(18.8)$ & 619 (27.9) & $349(27.6)$ \\
\hline Other race & & $111(1.6)$ & $52(1.6)$ & $34(1.5)$ & $25(2.0)$ \\
\hline Two or more races & & $261(3.9)$ & $122(3.7)$ & $80(3.6)$ & $59(4.7)$ \\
\hline Sexual Orientation $^{\mathbf{b}}$ & 5244 & & & & \\
\hline Heterosexual/Straight & & $4289(81.8)$ & $2191(90.1)$ & $1363(77.8)$ & 735 (69.3) \\
\hline Homosexual/Gay/Lesbian/Queer/"Down-Lo" & & $62(1.2)$ & $13(0.5)$ & $22(1.3)$ & $27(2.6)$ \\
\hline Bisexual/Other & & $868(16.6)$ & $219(9.0)$ & $356(20.3)$ & $293(27.6)$ \\
\hline Refused/Missing & & $25(0.5)$ & $8(0.3)$ & $12(0.7)$ & $5(0.5)$ \\
\hline Education & 6781 & & & & \\
\hline High school or less & & $5270(77.7)$ & $2587(78.6)$ & $1710(77.0)$ & $973(76.8)$ \\
\hline Some college & & $1351(19.9)$ & $635(19.3)$ & $456(20.5)$ & $260(20.5)$ \\
\hline College graduate or above & & $157(2.3)$ & $67(2.0)$ & $56(2.5)$ & $34(2.7)$ \\
\hline Refused/Missing & & $3(<0.1)$ & $3(0.1)$ & 0 & 0 \\
\hline Risk Behaviors $^{c}$ & 6781 & & & & \\
\hline Number of sex partners & & $1(1-3)$ & $1(1-2)$ & $2(1-3)$ & $2(1-4)$ \\
\hline Unprotected sex & & $5435(80.2)$ & $2528(76.8)$ & $1845(83.0)$ & $1062(83.8)$ \\
\hline Injection Drug Use & & & & & \\
\hline Ever IDU & & $976(14.4)$ & $280(8.5)$ & $231(10.4)$ & $465(36.7)$ \\
\hline Recent IDU & & $355(5.2)$ & - & $64(2.9)$ & $291(23.0)$ \\
\hline Substance Use ${ }^{c}$ & 6781 & & & & \\
\hline Alcohol & & $4142(61.1)$ & $1116(33.9)$ & $1946(87.6)$ & $1080(85.2)$ \\
\hline Binge alcohol & & $2734(40.3)$ & - & $1787(80.4)$ & $947(74.7)$ \\
\hline Cocaine/crack & & $907(13.4)$ & - & $107(4.8)$ & $800(63.1)$ \\
\hline Illicit opioids & & $917(13.5)$ & - & $178(8.0)$ & $739(58.3)$ \\
\hline Methamphetamine/stimulants & & $361(5.3)$ & - & $47(2.1)$ & $314(24.8)$ \\
\hline Cannabis & & $2370(35.0)$ & $734(22.3)$ & $896(40.3)$ & $740(58.4)$ \\
\hline Other & & $628(9.3)$ & - & $103(4.6)$ & $525(41.4)$ \\
\hline
\end{tabular}

Data presented as median (IQR) or $\mathrm{n}(\%)$ - percent may not sum to 100 due to rounding

a None included participants who reported no binge alcohol use or illicit drug use (non-binge alcohol use and cannabis use allowed)

${ }^{b}$ Sexual orientation was not collected in one study (BRIGHT)

c Reference period: past 30 or 90 days (see Table 1)

multivariable relative risk regression with robust confidence intervals to examine the relationship between CS among PWUS before/during sex compared to those who did not. Final models included age, race/ethnicity, and gender. Again, pooled effect estimates were calculated using traditional fixed-effects meta-analysis [40]. Additional analyses of CS among PWUS before/during sex compared to those who did not were performed after stratifying by type of sex. We assessed interaction between type of sex and substance use before and during sex as well, with the same limitation as previously mentioned.

\section{Time frame sensitivity analysis}

We performed a time-frame sensitivity analysis to assess the potential effect of heterogenous recall periods. 


\section{Results}

\section{Recent substance use}

Of the 6781 sexually active participants in the pooled analyses, median age of participants was 33 years (interquartile range (IQR): 26-45), 82\% were male, and the majority had a high school education or less (78\%). Approximately half $(52 \%)$ of the included participants reported substance use, with $19 \%$ reporting polysubstance use during the reference period (Table 2, see Supplement Table 1 for demographic differences broken down by study). PWUS differed on some demographic characteristics from non-users. Single- and poly-substance users, compared to non-users, reported more sexual partners on average and more often identified as something other than heterosexual, despite reporting heterosexual sex. Polysubstance users, compared to both nonusers and single-substance users, were more likely to be male ( $90 \%$ vs. 80 and $82 \%$, respectively), older (37 years vs. 32 and 34 years, respectively), and white (23\% vs. 8 and $9 \%$, respectively). The most commonly reported substances among single-substance users were binge alcohol (80\%), followed by illicit opioids (8\%), cocaine/ crack (5\%), and other substances (5\%). The most commonly reported substances among polysubstance users were binge alcohol (75\%), followed by cocaine/crack (63\%), illicit opioids (58\%), and other substances (41\%).

In regression analyses adjusted for demographic variables, PWUS were significantly more likely to engage in CS compared to non-users. Single-substance users were $8 \%$ more likely (95\% confidence interval (CI): 5-11\%, $p<0.001)$ to report recent CS and polysubstance users 9\% more likely (95\% CI: $5-13 \%, \mathrm{p}<0.001$ ) to engage in this sexual risk behavior. A comparison of polysubstance users to single-substance users found no significant difference in likelihood of engaging in CS ( $R R=1.02,95 \%$ CI: $0.99-1.05, p=0.26$ ) (Table 3 ). There was no significant interaction by age and SU (results not shown). We also performed this analysis with only illicit substance use as the exposure (binge alcohol use moved to referent group), and inference did not change (see Table 3). As individual substances, binge alcohol, cocaine/crack, and illicit opioid use were each associated with CS $[p=.04$ (95\% CI:1.00-1.07), $p=.02$ (95\% CI:1.01-1.08), and $p=$ .006 (95\% CI:1.02-1.09), respectively] (see Supplement Table 2).

Type of sex was associated with CS, with participants reporting vaginal and anal sex $21 \%$ more likely (95\% CI: $16-26 \%)$ to engage in CS compared to those reporting vaginal sex only $(p<0.001)$. Among participants having only vaginal sex, use of any substances was associated with a higher likelihood of CS compared to non-users, with single-substance users 9\% more likely (95\% CI: 5$14 \%, p<0.001)$ and polysubstance users $10 \%$ more likely (95\% CI: $5-15 \%, p<0.001$ ) to report CS. Among participants having both vaginal and anal sex, substance use also increased the likelihood of CS compared to non-users, with single-substance users 5\% more likely (95\% CI: 2-9\%, $p=0.004$ ) and polysubstance users $8 \%$ more likely (95\% CI: $4-12 \%, p<0.001)$ to report CS (Table 3). There was no significant interaction between type of sex and substance use category (results not shown).

Partner(s') self-reported HIV status was also associated with CS, with an 8\% lower likelihood (95\% CI: 2-14\%, $p=0.01$ ) of CS among participants reporting HIV-status unknown partners only compared to exclusively HIVnegative partners and a $11 \%$ higher likelihood (95\% CI: $4-19 \%, p=0.001)$ of CS among participants reporting both HIV-negative and HIV-status unknown partners compared to exclusively HIV-negative partners. Substance use was significantly associated with higher likelihood of CS among participants reporting exclusively HIV-negative partners and participants reporting both HIV-negative and HIV-status unknown partners, but not among participants reporting HIV-status unknown partners only. Use of any substances increased the likelihood of CS by $8 \%(95 \% \mathrm{CI}: 2-13 \%, p=0.004)$ for singlesubstance users and 7\% (95\% CI: $1-14 \%, p=0.02$ ) for polysubstance users compared to non-users among participants reporting exclusively HIV-negative partners. Use of any substances increased the likelihood of CS by 9\% (95\% CI: $1-18 \%, p=0.03$ ) for single-substance users and $13 \%$ (95\% CI: $6-20 \%, p<0.001)$ for polysubstance users compared to non-users among participants reporting HIV-negative and HIV-status unknown partners (Table 3). There was no significant interaction between partner(s)' HIV status and substance use category (results not shown).

For individual study estimates and meta-analytic forest plots for all associations presented for recent substance use, see Supplemental Figures 1, 2, 3, 4, 5, 6, 7, 8 and 9.

\section{Substance use before or during sex}

Among participants $(n=2915)$ that had information on substance use before/during sex and CS during the reference period, median age was 40 (IQR: 28-49), 69\% male, and most had high school education or less $(77 \%)$. Just over half (52\%) of the participants reported substance use before/during sex (Table 4, see Supplement Table 3 for demographics broken down by study). Similar to what we observed with recent PWUS, participants who used substances before/during sex reported more sexual partners on average and despite reporting heterosexual behavior more often identified as something other than heterosexual. Additionally, those who used substances before/during sex reported higher rates of use across all substance categories, had higher rates of injection drug use (6\% vs. $1 \%)$, and tended to be male $(84 \%$ 
Table 3 Recent substance use and condomless sex

\begin{tabular}{|c|c|c|c|}
\hline Recent substance use & RR & $95 \% \mathrm{Cl}$ & $p$-value \\
\hline \multicolumn{4}{|l|}{ Overall } \\
\hline$N_{0 n e}^{a}$ & Ref & - & - \\
\hline Single substance & 1.08 & $1.05-1.11$ & $<0.001$ \\
\hline Polysubstance & 1.09 & $1.05-1.13$ & $<0.001$ \\
\hline Single- vs. poly-substance & 1.02 & $0.99-1.05$ & 0.26 \\
\hline \multicolumn{4}{|l|}{ Overall - Illicit substance use only } \\
\hline None $^{b}$ & Ref & - & - \\
\hline Single substance & 1.06 & $1.02-1.09$ & 0.002 \\
\hline Polysubstance & 1.09 & $1.05-1.13$ & $<0.001$ \\
\hline Single- vs. poly-substance & 1.01 & $0.97-1.05$ & 0.68 \\
\hline \multicolumn{4}{|l|}{ By type of sex } \\
\hline Vaginal sex only & Ref & - & - \\
\hline Vaginal and anal sex & 1.21 & $1.16-1.26$ & $<0.001$ \\
\hline \multicolumn{4}{|l|}{ Vaginal sex only } \\
\hline None $^{a}$ & Ref & - & - \\
\hline Single substance & 1.09 & $1.05-1.14$ & $<0.001$ \\
\hline Polysubstance & 1.10 & $1.05-1.15$ & $<0.001$ \\
\hline Single- vs. poly-substance & 1.01 & $0.96-1.05$ & 0.81 \\
\hline \multicolumn{4}{|l|}{ Vaginal and anal sex } \\
\hline None $^{a}$ & Ref & - & - \\
\hline Single substance & 1.05 & $1.02-1.09$ & 0.004 \\
\hline Polysubstance & 1.08 & $1.04-1.12$ & $<0.001$ \\
\hline Single- vs. poly-substance & 1.03 & $0.99-1.06$ & 0.12 \\
\hline \multicolumn{4}{|l|}{ By HIV status of partner } \\
\hline HIV-negative partners only & Ref & - & - \\
\hline HIV-unknown partners only & 0.92 & $0.86-0.98$ & 0.01 \\
\hline HIV-negative \& HIV-unknown partners only & 1.11 & $1.04-1.19$ & 0.001 \\
\hline \multicolumn{4}{|l|}{ HIV-negative partners only } \\
\hline None $^{a}$ & Ref & & \\
\hline Single substance & 1.08 & $1.02-1.13$ & 0.004 \\
\hline Polysubstance & 1.07 & $1.01-1.14$ & 0.02 \\
\hline Single- vs. poly-substance & 0.99 & $0.94-1.05$ & 0.81 \\
\hline \multicolumn{4}{|l|}{ HIV-unknown partners only } \\
\hline None $^{a}$ & Ref & - & - \\
\hline Single substance & 1.04 & $0.95-1.13$ & 0.39 \\
\hline Polysubstance & 0.97 & $0.88-1.07$ & 0.57 \\
\hline Single- vs. poly-substance & 0.94 & $0.85-1.03$ & 0.20 \\
\hline \multicolumn{4}{|l|}{ HIV-negative \& HIV-unknown partners only } \\
\hline None $^{a}$ & Ref & - & - \\
\hline Single substance & 1.09 & $1.01-1.18$ & 0.03 \\
\hline Polysubstance & 1.13 & $1.06-1.20$ & $<0.001$ \\
\hline Single- vs. poly-substance & 1.04 & $0.98-1.10$ & 0.22 \\
\hline
\end{tabular}

Abbreviations: $\mathrm{Cl}$ Confidence interval, $R R$ Relative risk

Models adjusted for age, race/ethnicity, and gender

${ }^{a}$ None included participants who reported no binge alcohol use or illicit drug use (non-binge alcohol use and cannabis use allowed)

${ }^{b}$ None included participants who reported no illicit drug use (any alcohol use and cannabis use allowed) 
Table 4 Demographic characteristics among those using substances before or during sex

\begin{tabular}{|c|c|c|c|c|}
\hline & & \multirow[b]{2}{*}{ Total } & \multicolumn{2}{|c|}{ Substance use before/during sex } \\
\hline & & & No & Yes \\
\hline $\mathrm{N}$ & $\mathrm{N}$ & 2915 & $1397(47.9)$ & $1518(52.1)$ \\
\hline Male & 2915 & $2021(69.3)$ & $758(54.3)$ & $1263(83.2)$ \\
\hline Age & 2915 & $40(28-49)$ & $37(26-48)$ & $41(29-49)$ \\
\hline Race/Ethnicity & 2915 & & & \\
\hline Black or African American & & $1701(58.4)$ & $912(65.3)$ & $789(52.0)$ \\
\hline White & & 0 & 0 & 0 \\
\hline Hispanic or Latino (alone or in combination with race) & & $1169(40.1)$ & $460(32.9)$ & $709(46.7)$ \\
\hline Two or more races & & $45(1.5)$ & $25(1.8)$ & $20(1.3)$ \\
\hline Sexual Orientation & 2915 & & & \\
\hline Heterosexual/Straight & & $2002(68.7)$ & $1168(83.6)$ & $834(54.9)$ \\
\hline Homosexual/Gay/Lesbian/Queer/Down-Lo & & $55(1.9)$ & $13(0.9)$ & $42(2.8)$ \\
\hline Bisexual/Other & & $843(28.9)$ & $212(15.2)$ & $631(41.6)$ \\
\hline Refused/DK/Missing & & $15(0.5)$ & $4(0.3)$ & $11(0.7)$ \\
\hline Education & 2915 & & & \\
\hline High school or less & & $2251(77.2)$ & $1084(77.6)$ & $1167(76.9)$ \\
\hline Some college & & $572(19.6)$ & $278(19.9)$ & $294(19.4)$ \\
\hline College graduate or above & & $91(3.1)$ & $34(2.4)$ & $57(3.8)$ \\
\hline Refused/DK/Missing & & $1(<0.1)$ & $1(0.1)$ & 0 \\
\hline Risk Behaviors $^{a}$ & 2915 & & & \\
\hline Number of sex partners & & $2(1-3)$ & $1(1-2)$ & $2(1-3)$ \\
\hline Unprotected sex & & $2425(83.2)$ & $1110(79.5)$ & $1315(86.6)$ \\
\hline \multicolumn{5}{|l|}{ Injection Drug Use } \\
\hline Ever IDU & & $371(12.7)$ & $116(8.3)$ & $255(16.8)$ \\
\hline Recent IDU & & $92(3.2)$ & $8(0.6)$ & $84(5.5)$ \\
\hline Substance Use ${ }^{a}$ & 2915 & & & \\
\hline Alcohol & & $2133(73.2)$ & $812(58.1)$ & $1321(87.0)$ \\
\hline Binge alcohol & & $1419(48.7)$ & $437(31.3)$ & $982(64.7)$ \\
\hline Cocaine/crack & & $334(11.5)$ & $19(1.4)$ & $315(20.8)$ \\
\hline Illicit opioids & & $285(9.8)$ & $17(1.2)$ & $268(17.7)$ \\
\hline Methamphetamine/stimulants & & $73(2.5)$ & $10(0.7)$ & $63(4.2)$ \\
\hline Cannabis & & 899 (30.8) & $192(13.7)$ & $707(46.6)$ \\
\hline Other & & $180(6.2)$ & $19(1.4)$ & $161(10.6)$ \\
\hline Polysubstance & & $1039(35.6)$ & $175(12.5)$ & $864(56.9)$ \\
\hline
\end{tabular}

Data presented as median (IQR) or $n(\%)$ - percent may not sum to 100 due to rounding

${ }^{\text {a }}$ Reference period: past 30 days

vs. $54 \%$ ) and Hispanic or Latino ( $47 \%$ vs. $33 \%$ ). The most commonly reported substances used before/during sex were binge alcohol (65\%), polysubstance use (57\%), cocaine/crack (21\%), and illicit opioids (18\%).

In regression analyses adjusted for demographic variables, substance use before/during sex was significantly associated with CS, with a $16 \%$ increased likelihood (95\% CI: $12-20 \%, p<0.001)$ of CS compared to participants that did not use substances during sex (Table 5). The association between substance use during/before sex and
CS did not change across age levels (results not shown). There was no significant interaction by age and substance use before/during sex (results not shown).

Again, type of sex was associated with CS, with an $18 \%$ higher likelihood ( $95 \%$ CI: $11-26 \%, \mathrm{p}<0.001$ ) of CS among participants reporting vaginal and anal sex compared to vaginal sex only. Among participants having only vaginal sex, consumption of one or more substances during sex increased the likelihood of CS by $20 \%$ (95\% CI: $12-29 \%, \mathrm{p}<0.001$ ). Among participants having 
Table 5 Substance use before or during sex and condomless sex

\begin{tabular}{llll}
\hline Substance use before/during sex & RR & $95 \% \mathrm{Cl}$ & p-value \\
\hline Overall & & & \\
$\quad$ No & Ref & - & - \\
Yes & 1.16 & $1.12-1.20$ & $<0.001$ \\
By type of sex & & & \\
$\quad$ Vaginal sex only & Ref & - & - \\
$\quad$ Vaginal and anal sex & 1.18 & $1.11-1.26$ & $<0.001$ \\
Vaginal sex only & & & \\
No & Ref & - & - \\
Yes & 1.20 & $1.12-1.29$ & $<0.001$ \\
Vaginal and anal sex & & & \\
No & Ref & - & - \\
Yes & 1.07 & $1.03-1.11$ & 0.002 \\
\hline
\end{tabular}

Abbreviations: $\mathrm{Cl}$ Confidence interval, $R R$ Relative risk

Models adjusted for age, race/ethnicity, and gender

both vaginal and anal sex, consumption of one or more substances during sex increased the likelihood of CS by $7 \%$ (95\% CI: $3-11 \%, p=0.002$ ) (Table 5). There was no significant interaction between type of sex and substance use before/during sex (results not shown).

For individual study estimates and meta-analytic forest plots for all associations presented for substance use before/during sex, see Supplemental Figures 10, 11, 12 and 13.

\section{Time frame sensitivity analysis}

While the 30-day recall period showed stronger associations, overall inference and patterns were similar (see Supplement Tables 4 and 5).

\section{Sensitivity analyses with Cannabis}

Sensitivity analyses found that cannabis was not associated with CS when used in the absence of other substances $\quad(\mathrm{RR}=0.99, \quad 95 \% \quad \mathrm{CI}: \quad 0.94-1.04, \quad p=0.61)$ (Supplement Table 6). Additionally, even with increasing frequency of use, cannabis was not associated with engagement in CS (RR range $=1.00-1.05, p$-value range: 0.24-0.92) (Supplement Table 7).

\section{Discussion}

In this large, cross-sectional study with a diverse sample of substance-using HIV-uninfected adults reporting heterosexual sex, we note several key findings. The use of substances excluding cannabis, was associated with CS relative to non-substance use. This was true of both recent substance use (in either the previous 30 or 90 days), as well as substance use before/during sex. Recent polysubstance use also increased CS risk, though not more so than recent single-substance use. The lack of excess risk among polysubstance compared to single-substance users does not align with findings from a large study of HIV-uninfected MSM [34]. Before or during sex, any substance use, with the exception of cannabis, increased CS. Notably, age did not modify the effect between SU and increased risk of CS. The finding that most substances increase CS contrasts from that of a recent systemic review of substance administration studies, which found alcohol to be independently associated with sexual risk behavior, that cocaine increased it, and cannabis decreased it [41].

A key finding is the strong correlation between concurrent sexual and drug use risk. Previous studies using a variety of methods inconsistently show a temporal relationship between concurrent drug/alcohol use and sexual risk [42], likely due to pitfalls and differences in collection methods. Timeline follow-back, with 14- or 30-day recall, is fraught with recall bias [43]. Daily diaries are constrained because entries are not made in near real-time and do not measure intentions before events occur [44]. Newer event-level methods, like ecological momentary assessment $[45,46]$, may further disentangle this association.

Cannabis use did not increase the risk of CS, neither in the context of recent use nor before/during sex. Frequency of cannabis use did not change CS risk. While a similar lack of effect on CS and STI outcomes has been apparent in studies of adolescents, young adults, and MSM [42, 47-52],, other studies have found the opposite [27-30]. Several wide-ranging factors may be driving differences in findings; these include population-level factors (e.g., age, gender, sexual orientation); social factors (e.g., relationship type and duration, power dynamics surrounding sexual behavior, and the role of intentionality to use condoms in the context of cannabis use); factors specific to cannabis and its use itself (e.g., drug potency, dependency, tolerance to its effects); study design factors, such as social desirability bias from particular data collection methods. More research, ideally a meta-analytic review, or a large representative sample of the whole source population with careful sub-group testing is needed to help reconcile discrepancies between findings.

Due to mixed findings of a correlation between cannabis use and CS in the wider literature, findings here are restricted to an older population than previously reported. Our relatively mature adult cohort, many of whom represent highly marginalized populations and have long histories of cannabis and other substance use, may have developed a tolerance to the effects of cannabis. Frequent cannabis users have shown an increased tolerance to its impairing effects [53], even when also intoxicated by alcohol [54]; members of our cohort may have developed an ability to function under its influence 
or under that of multiple combined substances. Results may differ among less-experienced users such as youth/ adolescents, for whom the effects of cannabis have been found to be particularly detrimental to brain function $[55,56]$; indeed, a meta-analysis of event-based studies found cannabis use around the time of intercourse increased the odds of CS among adolescents, but not adults [57]. Due to the ambiguity of cannabis's role in CS across populations relative to other non-cannabis substances, we recommend that future analyses of polysubstance impact on CS analyze cannabis use independently from other grouped substances in order to avoid potentially underestimating the impact of non-cannabis substances.

We found that having exclusively HIV-negative partner/s increased the likelihood of CS. Having exclusively HIV-status unknown partners did not, even in the context of substance use before/during sex. Assuming that not knowing a partner's HIV status implies less overall familiarity with the partner, a possible explanation for this finding is that lower partner familiarity is associated with increased condom use, perhaps indicative of greater concern or consciousness for potential HIV/STI transmission risk and/or pregnancy risk. Conversely, the higher rate of CS observed among those with exclusively HIV-negative partners may in part reflect practices within long-term and/or perceivably monogamous partnerships in which STI/HIV transmission is thought to be of low concern, diminishing the felt need to use condoms. Among those with a mix of HIV-status unknown and HIV-negative partners, CS was also higher. However, with this group, we lacked data regarding with which partners (HIV-negative or HIV-status unknown) condoms were and were not used. Our findings among those with partner/s of exclusive serostatus (all negative or all unknown) suggest that the high rate of CS among those with both types of partners is driven primarily by the low condom use observed between HIV-negative partners.

Based on these findings, it may be advisable for HIV/ STI prevention efforts as well as care providers to assess HIV/STI transmission risk among those with exclusively HIV-negative partners, particularly non-cannabis using PWUS, and to assess HIV/STI transmission risk and prevention practices among those reporting any partners for whom HIV/STI status is unknown. Of concern, we found that CS was more likely to occur among those having anal sex in addition to vaginal sex, compared to those reporting exclusively vaginal sex; substance use increased likelihood of CS for both of these groups. This has particularly strong implications for HIV transmission risk, given the higher risk of infection known to occur in anal compared to vaginal sex, underscoring the need to identify such risk behaviors, including recent substance use, at point-of-care. It is also essential that gender dynamics and sexual power be considered with sensitive instrumentation and interventions for those who might report lack of personal agency for protection, so that interventions could address these differentials and help empower participants with more at-risk behaviors. Finally, we note that participant age did not have an effect on likelihood of CS, neither for recent PWUS nor those who used before/during sex, indicating a need to address sexual risk behavior across the life span.

\section{Strengths}

A strength of our study is its sample size and the demographic and geographic diversity of participants.

\section{Limitations}

We note that study sites did not use uniform time frames in their measures. Additionally, because different studies used different instruments, collection of covariates differed by study and data were not necessarily available for all potential confounders. Because the data were cross-sectional, only associations and not causation could be determined. While we used CS as our outcome, we cannot infer any increased level of developing a STI. We note that because nuanced data was not available on partner serosorting, condom use behavior lacked context. We also note the possibility self-report bias in the areas of substance use, sexual behavior, and HIV negative serostatus. In addition, this paper focuses on condomless sex. However, clearly there are other approaches to address in order to reduce HIV/STI transmission, including the use of pre-exposure prophylaxis and needle exchange programs for injection drug use.

\section{Conclusion}

With the exception of cannabis, any recent substance use was associated with an increased likelihood of engaging in CS, whether used in the past 30-90 days, or before/during sex. Polysubstance use, however, relative to single substance use, did not further elevate this risk. Higher frequency of cannabis use did not increase the risk of CS. Future studies of the impact of substance use on behavior should consider analyzing cannabis use independently from other substances. For non-cannabisusing PWUS, CS was higher for participants with exclusively HIV-negative partners and for those reporting both anal and vaginal sex in the past 30 or 90 days. Conversely, participants reporting exclusively HIV-status unknown partners in the same reference period did not have a higher risk of CS. STI prevention efforts among non-cannabis-using PWUS should not overlook STI risk assessment for those reporting HIV-negative partners. 


\section{Supplementary Information}

The online version contains supplementary material available at https://doi. org/10.1186/s12889-021-12026-7.

\section{Additional file 1.}

\section{Acknowledgements}

The authors would like to thank the research teams associated with the Seek, Test, Treat, and Retain Data Collection and Harmonization Initiative whose collaboration has made this project possible and particularly the participants in the individual STTR studies for their valuable contributions. A full list of participating STTR investigators and institutions can be found at http://www.sttr-hiv.org. Research presented in this paper is the result of secondary data analyses associated with the STTR Data Collection and Harmonization Initiative and was supported by U01DA037702 from the National Institute on Drug Abuse (NIDA). For this manuscript, we harmonized data from the following grants: BCAP1 R01DA032083, BRIGHT1 R01DA030771, STAR R01DA032100, and STTS R01DA030796. The views expressed in this paper are those of the authors and do not reflect those of the National Institute on Drug Abuse or the National Institutes of Health.

\section{Authors' contributions}

$R F, H C, J D, R N, B W$, and ET generated the concept of interest and the approach to analysis. Data was curated by BW, JD, SK, RN, ET, WE, CC, DS, and JR. The formal analysis was performed by BW, RN, and ET, with oversight by JD and HC. BW performed STTR project coordination and management. $\mathrm{RF}, \mathrm{BW}$, and EF authored the original draft. In subsequent drafts. RF led authorship on all subsequent and final drafts. Editing and review of subsequent drafts was performed by RF, BW, RN, HC, JD, EF, FA, AC, CC, CD, $A D, W E, S K, I K, K M, S M, L O, V Q, J R, D S, S S, F T$, and WW. All authors read and approved the final manuscript.

\section{Funding}

This work was supported by U01DA037702 from the National Institute on Drug Abuse (NIDA). For this manuscript, we harmonized data from the following grants: BCAP1 R01DA032083, BRIGHT1 R01DA030771, STAR R01DA032100, and STTS R01DA030796. The views expressed in this paper are those of the authors and do not reflect those of the National Institute on Drug Abuse or the National Institutes of Health.

\section{Availability of data and materials}

Data and materials are archived by both the DCC and NIDA. They can be made available upon reasonable request, with a concept proposal and fully executed data use agreement (due to the sensitivity of the data). Interested investigators can email jacd@uw.edu for more details.

\section{Declarations}

Ethics approval and consent to participate

Human subject research approval for this research was obtained via the each associated institution's Institutional Review Board:

- BCAP, New York University

- BRIGHT, Friends Research Institute

- STAR, Columbia University

- STTS, University of Wisconsin-Milwaukee

Written informed consent was obtained from all study participants.

\section{Consent for publication}

Not applicable.

\section{Competing interests}

S. Springer received consultation payment from Alkermes Inc. for scientific expertise consulting. No other disclosures.

\section{Author details}

${ }^{1}$ UW Center for AIDS Research, Harborview Medical Center, 325 Ninth Avenue, Box 359931, Seattle, WA 98104-2499, USA. ${ }^{2}$ Yale University AIDS
Program, 135 College Street, Suite 323, New Haven, CT 06510-2283, USA. ${ }^{3}$ Division of Prevention Science and Community Health, University of Miami, 1120 NW 14th St, Miami, FL 33136, USA. ${ }^{4}$ Center for Drug Use and HIV Research, NYU School of Global Public Health, 665 Broadway, 11th Floor, New York, NY 10012, USA. ${ }^{5}$ Rollins School of Public Health, Emory University, 1518 Clifton Road, NE Room 7011, Atlanta, GA 30322, USA. ${ }^{6}$ Fred Hutchinson Cancer Research Center, HIV Vaccine Trials Network, Box 358080 (LE 500), Seattle, WA 98109, USA. ${ }^{7}$ Mailman School of Public Health, Columbia University, 722 West 168th Street, 13th floor, New York, NY 10032, USA. ${ }^{8}$ National Institute on Drug Abuse, 6001 Executive Blvd, Rockville, Maryland 20852, USA. ${ }^{9}$ Department of Epidemiology and Biostatistics, Milken Institute School of Public Health, George Washington University, 950 New Hampshire Ave NW \#2, Washington, DC 20052, USA. ${ }^{10}$ The Fenway Institute, 1340 Boylston Street, Boston, MA 02215, USA. ${ }^{11}$ Johns Hopkins University, Bloomberg School of Public Health, 615 N. Wolfe Street, Baltimore, Maryland 21205, USA. ${ }^{12}$ School of Public Health, University of Illinois at Chicago, 1603 W. Taylor St, Chicago, IL, USA. ${ }^{13}$ Department of Epidemiology, Bloomberg School of Public Health, Johns Hopkins University, 615 N. Wolfe Street, Baltimore, Maryland 21205, USA. ${ }^{14}$ Center for Prisoner Health and Human Rights, Immunology Center, The Miriam Hospital, Warren Alpert Medical School, Brown University, 1125 North Main St, Providence, RI 02904, USA. ${ }^{15}$ Department of Global Community Health and Behavioral Sciences, School of Public Health and Tropical Medicine, Tulane University, 1440 Canal St, Suite 2200, New Orleans, LA 70112, USA. ${ }^{16}$ Department of Internal Medicine, School of Medicine, Yale University, 135 College Street, New Haven, CT 06510, USA. ${ }^{17}$ Center for Advancing Correctional Excellence, Institute of Biohealth Innovation, George Mason University, 4461 Rockfish Creek Lane, Fairfax, VA 22030, USA. ${ }^{18}$ Department of Health Policy and Management, Gillings School of Public Health, University of North Carolina Chapel Hill, 135 Dauer Dr, Chapel Hill, NC 27599, USA. ${ }^{19}$ College of Pharmacy, University of Manitoba, Apotex Centre, 750 McDermot Avenue, Winnipeg, Manitoba R3E 0T5, Canada.

Received: 8 June 2020 Accepted: 15 October 2021

Published online: 04 November 2021

\section{References}

1. Centers for Disease Control. Communities in Crisis: Is There a Generalized HIV Epidemic in Impoverished Urban Areas of the United States? In: Centers for Disease Control; 2017.

2. Millett GA, Flores SA, Peterson JL, Bakeman R. Explaining disparities in HIV infection among black and white men who have sex with men: a metaanalysis of HIV risk behaviors. AIDS. 2007;21(15):2083-91. https://doi.org/10.1 097/QAD.0b013e3282e9a64b.

3. Baral SD, Poteat T, Stromdahl S, Wirtz AL, Guadamuz TE, Beyrer C. Worldwide burden of HIV in transgender women: a systematic review and meta-analysis. Lancet Infect Dis. 2013;13(3):214-22. https://doi.org/10.1016/ S1473-3099(12)70315-8.

4. Herbst JH, Jacobs ED, Finlayson TJ, McKleroy VS, Neumann MS, Crepaz N, et al. Estimating HIV prevalence and risk behaviors of transgender persons in the United States: a systematic review. AIDS Behav. 2008;12(1):1-17. https://doi.org/10.1007/s10461-007-9299-3.

5. Reback CJ, Fletcher JB. HIV prevalence, substance use, and sexual risk behaviors among transgender women recruited through outreach. AIDS Behav. 2014;18(7):1359-67. https://doi.org/10.1007/s10461-013-0657-z.

6. Center for Disease Control. STDs in men who have sex with men. In: Center for Disease Control; 2014.

7. Center for Disease Control. Fact sheet: HIV among African Americans. In: Center for Disease Control; 2016.

8. Centers for Disease Control. HIV in the United States: At A Glance. In: Centers for Disease Control; 2017.

9. Centers for Disease Control. HIV among incarcerated populations. In: Centers for Disease Control; 2018.

10. New York City Department of Health and Mental Hygiene. Substance use and sexual risk among men who have sex with men, injection drug users, and high-risk heterosexuals: resutls from the national HIV behavioral surveillance study in new York City. In: New York City Department of Health and Mental Hygiene; 2010.

11. Lacefield K, Negy C, Schrader RM, Kuhlman C. Comparing psychosocial correlates of Condomless anal sex in HIV-diagnosed and HIV-nondiagnosed men who have sex with men: a series of Meta-analyses of studies from 
1993-2013. LGBT Health. 2015;2(3):200-20. https://doi.org/10.1089/lgbt.2014. 0069.

12. Hittner JB. Meta-analysis of the association between methamphetamine use and high-risk sexual behavior among heterosexuals. Psychol Addict Behav. 2016;30(2):147-57. https://doi.org/10.1037/adb0000162.

13. Stall R, Paul JP, Greenwood G, Pollack LM, Bein E, Crosby GM, et al. Alcohol use, drug use and alcohol-related problems among men who have sex with men: the Urban Men's health study. Addiction. 2001;96(11):1589-601. https://doi.org/10.1046/j.1360-0443.2001.961115896.x.

14. Kipping RR, Smith M, Heron J, Hickman M, Campbell R. Multiple risk behaviour in adolescence and socio-economic status: findings from a UK birth cohort. Eur J Pub Health. 2015;25(1):44-9. https://doi.org/10.1093/ eurpub/cku078.

15. Gore FM, Bloem PJ, Patton GC, Ferguson J, Joseph V, Coffey C, et al. Global burden of disease in young people aged 10-24 years: a systematic analysis. Lancet. 2011;377(9783):2093-102. https://doi.org/10.1016/S0140-6736(11 )60512-6.

16. Weinhardt LS, Carey MP. Does alcohol lead to sexual risk behavior? Findings from event-level research. Annu Rev Sex Res. 2000;11:125-57.

17. Kiene SM, Simbayi LC, Abrams A, Cloete A. Alcohol expectancies and inhibition conflict as moderators of the alcohol-unprotected sex relationship: event-level findings from a daily diary study among individuals living with HIV in Cape Town, South Africa. AIDS Behav. 2016;20(Suppl 1): S60-73. https://doi.org/10.1007/s10461-015-1157-0.

18. Kiene SM, Subramanian SV. Event-level association between alcohol use and unprotected sex during last sex: evidence from population-based surveys in sub-Saharan Africa. BMC Public Health. 2013;13(1):583. https://doi.org/10.11 86/1471-2458-13-583.

19. Leigh BC. Alcohol and condom use: a meta-analysis of event-level studies. Sex Transm Dis. 2002;29(8):476-82. https://doi.org/10.1097/00007435-2002 08000-00008.

20. Hensel DJ, Stupiansky NW, Orr DP, Fortenberry JD. Event-level marijuana use, alcohol use, and condom use among adolescent women. Sex Transm Dis. 2011;38(3):239-43. https://doi.org/10.1097/OLQ.0b013e3181f422ce.

21. Kerr DC, Washburn IJ, Morris MK, Lewis KA, Tiberio SS. Event-level associations of marijuana and heavy alcohol use with intercourse and condom use. J Stud Alcohol Drugs. 2015;76(5):733-7. https://doi.org/10.152 88/jsad.2015.76.733.

22. Lachowsky NJ, Tanner Z, Cui Z, Sereda P, Rich A, Jollimore J, et al. An eventlevel analysis of condom use during anal intercourse among self-reported human immunodeficiency virus-negative gay and bisexual men in a treatment as prevention environment. Sex Transm Dis. 2016;43(12):765-70. https://doi.org/10.1097/OLQ.0000000000000530.

23. Leigh BC, Ames SL, Stacy AW. Alcohol, drugs, and condom use among drug offenders: an event-based analysis. Drug Alcohol Depend. 2008;93(1-2):3842. https://doi.org/10.1016/j.drugalcdep.2007.08.012.

24. Pines HA, Gorbach PM, Weiss RE, Reback CJ, Landovitz RJ, Mutchler MG, et al. Individual-level, partnership-level, and sexual event-level predictors of condom use during receptive anal intercourse among HIV-negative men who have sex with men in Los Angeles. AIDS Behav. 2016;20(6):1315-26. https://doi.org/10.1007/s10461-015-1218-4

25. Williams AV, Hariga F. Systematic literature review on stimulant use and HIV (a) part 3/5 cocaine and crack-cocaine risk and transmission; 2017.

26. Zule WA, Oramasionwu C, Evon D, Hino S, Doherty IA, Bobashev GV, et al. Event-level analyses of sex-risk and injection-risk behaviors among nonmedical prescription opioid users. Am J Drug Alcohol Abuse. 2016;42(6): 689-97. https://doi.org/10.1080/00952990.2016.1174706.

27. Kingree $\mathrm{JB}, \mathrm{Betz} \mathrm{H}$. Risky sexual behavior in relation to marijuana and alcohol use among African-American, male adolescent detainees and their female partners. Drug Alcohol Depend. 2003;72(2):197-203. https://doi.org/1 0.1016/S0376-8716(03)00196-0.

28. Drumright LN, Little SJ, Strathdee SA, Slymen DJ, Araneta MR, Malcarne VL, et al. Unprotected anal intercourse and substance use among men who have sex with men with recent HIV infection. J Acquir Immune Defic Syndr. 2006;43(3):344-50. https://doi.org/10.1097/01.qai.0000230530.02212.86.

29. Hendershot CS, Magnan RE, Bryan AD. Associations of marijuana use and sex-related marijuana expectancies with HIV/STD risk behavior in high-risk adolescents. Psychol Addict Behav. 2010;24(3):404-14. https://doi.org/10.103 7/a0019844

30. Bryan AD, Schmiege SJ, Magnan RE. Marijuana use and risky sexual behavior among high-risk adolescents: trajectories, risk factors, and event-level relationships. Dev Psychol. 2012;48(5):1429-42. https://doi.org/10.1037/a002 7547.

31. Scott-Sheldon LA, Carey MP, Vanable PA, Senn TE, Coury-Doniger P, Urban MA. Alcohol consumption, drug use, and condom use among STD clinic patients. J Stud Alcohol Drugs. 2009;70(5):762-70. https://doi.org/10.15288/ jsad.2009.70.762.

32. Wechsberg WM, Myers B, Kline TL, Carney T, Browne FA, Novak SP. The Relationship of Alcohol and Other Drug Use Typologies to Sex Risk Behaviors among Vulnerable Women in Cape Town, South Africa. J AIDS Clin Res. 2012;S1(15). https://doi.org/10.4172/2155-6113.S1-015.

33. Purcell DW, Parsons JT, Halkitis PN, Mizuno Y, Woods WJ. Substance use and sexual transmission risk behavior of HIV-positive men who have sex with men. J Subst Abus. 2001;13(1-2):185-200. https://doi.org/10.1016/S0899-32 89(01)00072-4.

34. Santos GM, Coffin PO, Das M, Matheson T, DeMicco E, Raiford JL, et al. Doseresponse associations between number and frequency of substance use and high-risk sexual behaviors among HIV-negative substance-using men who have sex with men (SUMSM) in San Francisco. J Acquir Immune Defic Syndr. 2013:63(4):540-4. https://doi.org/10.1097/QAl.0b013e318293f10b.

35. Semple SJ, Strathdee SA, Zians J, Patterson TL. Sexual risk behavior associated with co-administration of methamphetamine and other drugs in a sample of HIV-positive men who have sex with men. Am J Addict. 2009; 18(1):65-72. https://doi.org/10.1080/10550490802544466.

36. Chandler R, Gordon MS, Kruszka B, Strand LN, Altice FL, Beckwith CG, et al. Cohort profile: seek, test, treat and retain United States criminal justice cohort. Subst Abuse Treat Prev Policy. 2017;12(1):24. https://doi.org/10.1186/ s13011-017-0107-4.

37. Chandler RK, Kahana SY, Fletcher B, Jones D, Finger MS, Aklin WM, et al. Data collection and harmonization in HIV research: the seek, test, treat, and retain initiative at the National Institute on Drug Abuse. Am J Public Health. 2015;105(12):2416-22. https://doi.org/10.2105/AJPH.2015.302788.

38. StataCorp. Stata Statistical Software: Release 14. College Station: StataCorp: 2015.

39. Zou G. A modified poisson regression approach to prospective studies with binary data. Am J Epidemiol. 2004;159(7):702-6. https://doi.org/10.1093/aje/ kwh090.

40. Rice K, Higgins J, Lumley T. A re-evaluation of fixed effect(s) meta-analysis. J R Stat Soc. 2017:181(1):205-27. https://doi.org/10.1111/rssa.12275.

41. Berry MS, Johnson MW. Does being drunk or high cause HIV sexual risk behavior? A systematic review of drug administration studies. Pharmacol Biochem Behav. 2018;164:125-38. https://doi.org/10.1016/j.pbb.2017.08.009.

42. Vosburgh HW, Mansergh G, Sullivan PS, Purcell DW. A review of the literature on event-level substance use and sexual risk behavior among men who have sex with men. AIDS Behav. 2012;16(6):1394-410. https://doi.org/1 0.1007/s10461-011-0131-8

43. Fiellin DA, McGinnis KA, Maisto SA, Justice AC, Bryant K. Measuring alcohol consumption using timeline Followback in non-treatment-seeking medical clinic patients with and without HIV infection: 7-, 14-, or 30-day recall. J Stud Alcohol Drugs. 2013;74(3):500-4. https://doi.org/10.15288/jsad.2013.74. 500.

44. Shiffman S. Ecological momentary assessment (EMA) in studies of substance use. Psychol Assess. 2009;21(4):486-97. https://doi.org/10.1037/a0017074.

45. Searles JS, Helzer JE, Walter DE. Comparison of drinking patterns measured by daily reports and timeline follow back. Psychol Addict Behav. 2000;14(3): 277-86. https://doi.org/10.1037/0893-164X.14.3.277.

46. Moskowitz DS, Young SN. Ecological momentary assessment: what it is and why it is a method of the future in clinical psychopharmacology. J Psychiatry Neuroscience. 2006;31(1):13-20.

47. Walsh JL, Fielder RL, Carey KB, Carey MP. Do alcohol and marijuana use decrease the probability of condom use for college women? I Sex Res. 2014;51(2):145-58. https://doi.org/10.1080/00224499.2013.821442.

48. McNall M, Remafedi G. Relationship of amphetamine and other substance use to unprotected intercourse among young men who have sex with men. Arch Pediatr Adolesc Med. 1999;153(11):1130-5. https://doi.org/10.1 001/archpedi.153.11.1130.

49. Brodbeck J, Matter M, Moggi F. Association between cannabis use and sexual risk behavior among young heterosexual adults. AIDS Behav. 2006; 10(5):599-605. https://doi.org/10.1007/s10461-006-9103-9.

50. Callahan TJ, Caldwell Hooper AE, Thayer RE, Magnan RE, Bryan AD. Relationships between marijuana dependence and condom use intentions 
and behavior among justice-involved adolescents. AIDS Behav. 2013;17(8): 2715-24. https://doi.org/10.1007/s10461-013-0417-0.

51. Rendina HJ, Moody RL, Ventuneac A, Grov C, Parsons JT. Aggregate and event-level associations between substance use and sexual behavior among gay and bisexual men: comparing retrospective and prospective data. Drug Alcohol Depend. 2015;154:199-207. https://doi.org/10.1016/j.drugalcdep.201 5.06.045.

52. Gorbach PM, Javanbakht M, Shover CL, Bolan RK, Ragsdale A, Shoptaw S. Associations between Cannabis use, sexual behavior, and sexually transmitted infections/human immunodeficiency virus in a cohort of Young men who have sex with men. Sex Transm Dis. 2019;46(2):105-11. https:// doi.org/10.1097/OLQ.0000000000000919.

53. Ramaekers JG, Theunissen EL, de Brouwer M, Toennes SW, Moeller MR Kauert G. Tolerance and cross-tolerance to neurocognitive effects of THC and alcohol in heavy cannabis users. Psychopharmacology. 2011;214(2):391401. https://doi.org/10.1007/s00213-010-2042-1.

54. Binder A. An experimental approach to driver evaluation using alcohol drinkers and marihuana smokers. Accid Anal Prev. 1971;3(4):237-56. https:// doi.org/10.1016/0001-4575(71)90002-9.

55. Jacobus J, Tapert SF. Effects of cannabis on the adolescent brain. Curr Pharm Des. 2014;20(13):2186-93. https://doi.org/10.2174/138161281131 99990426.

56. Camchong J, Lim KO, Kumra S. Adverse effects of Cannabis on adolescent brain development: a longitudinal study. Cereb Cortex. 2017;27(3):1922-30. https://doi.org/10.1093/cercor/bhw015.

57. Schumacher A, Marzell M, Toepp AJ, Schweizer ML. Association between marijuana use and condom use: a Meta-analysis of between-subject eventbased studies. J Stud Alcohol Drugs. 2018;79(3):361-9. https://doi.org/10.152 88/jsad.2018.79.361.

\section{Publisher's Note}

Springer Nature remains neutral with regard to jurisdictional claims in published maps and institutional affiliations.

Ready to submit your research? Choose BMC and benefit from:

- fast, convenient online submission

- thorough peer review by experienced researchers in your field

- rapid publication on acceptance

- support for research data, including large and complex data types

- gold Open Access which fosters wider collaboration and increased citations

- maximum visibility for your research: over $100 \mathrm{M}$ website views per year

At $\mathrm{BMC}$, research is always in progress.

Learn more biomedcentral.com/submissions 